\title{
ASSESSMENT OF ADHESION BETWEEN MINERAL AGGREGATE AND BITUMINOUS BINDER USING DIGITAL IMAGE ANALYSIS
}

\author{
JAN TREJBAL $^{a, *}$, ZDenĚK ProšEK ${ }^{a, b}$, Tereza VAlentováa ${ }^{a}$ \\ ${ }^{a}$ Czech Technical University in Prague, Faculty of Civil Engineering, Thákurova 7, 16629 Prague 6, Czech \\ Republic \\ ${ }^{b}$ University Centre for Energy Efficient Buildings of Technical University in Prague, Třinecká 1024, 273 43 \\ Buštěhrad, Czech Republic \\ * corresponding author: jan.trejbal@fsv.cvut.cz
}

\begin{abstract}
This work presents how to assess a rate of adhesion between bituminous binder and mineral aggregate. Asphalt mixtures composed from grade bitumen 50/70, reference or modified with adhesion promoters based on amines, and aggregate (Brant, Zbraslav, Skuteč - 8-16 mm) were made and then photographed. Three adhesion assessment approaches were applied: (i) standardized adhesion visual assessment, (ii) gray level thresholding, and (iii) entropy-based image segmentation, both evaluated from digital images. It was shown that adhesion between both Brant and Skuteč and reference binder, expressed as a rate of binder-coated area onto aggregate particles, was equal to ca. 50-70\%, while mixture composed from Zbraslav exhibited ca. 70-80\%. If adhesion promoters were used, these areas increased in all three cases up to 80-90\%. It was shown that results obtained using visual and entropy segmentation analysis were very similar, while these differed in comparison with gray-level thresholding.
\end{abstract}

KEYWORDS: Asphalt mixture, bituminous binder, adhesion promoters, interphase interaction.

\section{INTRODUCTION}

Asphalt mixtures are considered to be one of the most important material in many industries, especially in road structure engineering. After all, over $90 \%$ of roads in Europe are constructed from asphalt mixtures, as summarized by S. Liu et al. 11. It is therefore obvious that whatever damages of such roads cause many economical, traffic-safety, and traffic-comfort negative consequences.

One of the most common cause of pavement structure failures is so-called "stripping", i.e., lost of adhesion between bituminous binder film and mineral aggregate particles in dry conditions or in presence of water 2. This phenomenon is also known as "asphalt moisture damage". Once the adhesion between the two materials fails, water migrates between them and thus disallows their direct contact, as illustrated in Figure 1. This is associated with reducing of pavement strength, resulting in damages known as potholes and fatigue cracking. Therefore, water is considered to be one of the most enemy of asphalt mixtures. In asphalt mixtures, two types of water sources are known [3]:

- Internal: water is left in asphalt mixture with inadequately dried aggregate or with hot bitumen at the form of steam.

- External: water entering pavements made from asphalt mixtures because of poor drainage or highly wet subgrade.

In order to avoid the stripping, it is necessary to

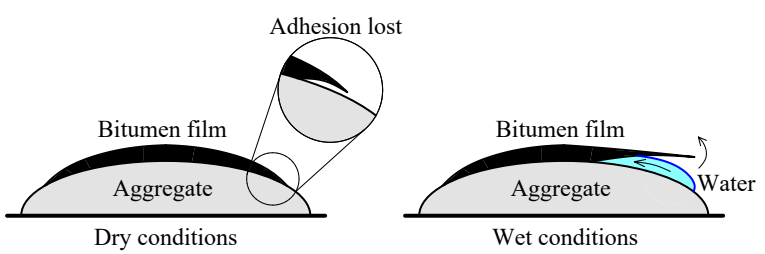

Figure 1. Adhesion lost between binder and aggregate in presence of water.

ensure a strong interphase interaction between the two materials and thus to prevent to water penetration between them. Unfortunately, the adhesion often fails due to physical properties of aggregate (surface smooth texture), occurrence of impurities (clay, dust), or unfavorable bitumen and aggregate chemistry. The last mentioned item seems to be the most problematic issue; binder exhibits weak chemical affinity for aggregate, whereas aggregate is typical for its strong affinity for water, especially if contains high amount of acidic type mineral rocks (high silica contents - quartz-based granites). Binder can be therefore replaced by water easily [3].

To avoid the phenomenon described above, the adhesion between the two materials can be enhanced using adhesion promoters - synthetic compounds or those from natural resources, mixed in trace amount to binder. Their role is to alter interface properties of both binder and aggregate. Their function is based on disruption of intermolecular interactions between 
water and aggregate surface. Consequently, contact energy between binder and aggregate is thus lower 4 .

With using of adhesion promoters, an essential question arises: how to quantify their function. Across both the technical and laboratory praxis, there are commonly used methods assessing adhesion between binder and aggregate that can be, in general, divided into following two groups:

- Mechanical testing: asphalt mixtures are made in dry conditions and then their mechanical properties are examined (modulus of elasticity, tensile and pressure strength, adhesion peeling tests, etc.). As the next step, those are exposed to water and then their mechanical properties are tested again. Such obtained results are mutually compared [5, 6].

- Laboratory interphase interaction testing: interaction between the two materials is tested in laboratory conditions, which cannot reflect many variable parameters like aggregate shape, surface, and so on (contact angle measurement, Wilhelmy method, etc.) 711$]$.

- Stripping rate observation: asphalt mixtures are made similarly to procedure described in the previous item but a rate of stripping is then assessed visually, ie., a rate between binder-coated and stripped areas on aggregate particles is observed (rolling bottle test, detachment in boiling water, etc.) [12, 13].

Stripping rate observation-based methods provide the most indicating results in terms of applicability and reliability. They are therefore most frequented across technical praxis, as summarized by Grönninger et al. 9]. However, an evaluation of these methods is based on subjective assessment of at least two evaluators, who estimate a degree of bitumen-coated area on aggregate visually. To overcome their subjective and so unconscious conclusions, some researchers have developed semi-automatic techniques. Källén et al. [14] and Lamperti et al. [15] employed methods based on gray level thresholding (GLT), assessing YUV or RGB color space. Although these techniques seems to be promising, their usage is limited due to bitumen glossy surfaces. Specularly reflected light from these surfaces causes over exposed areas in captured images. These areas merge in with light aggregates, so any GLTbased software is not able to recognize them correctly as binder-coated.

In order to overcome the issues connected with dark aggregate and over-exposed areas within images, software based on entropy image segmentation was employed. The software is able to assess the adhesion between the two materials even from under-exposed images, free from local over-expositions, but still containing detail drawings in dark parts, if captured properly. These images were used for digital image based analysis: gray level thresholding and entropybased image segmentation. Moreover, to compare such obtained results, standardized adhesion visual assessment was also executed.

\section{Asphalt mixtures}

\subsection{Aggregate}

Three types of mineral aggregate, crushed to the fraction of $8-16 \mathrm{~mm}$, were used with respect to the availability of natural aggregate sources in the Czech Republic. These three representatives are considered to be the most typical aggregate being used for purposes of asphalt mixture production in the Czech Republic. Moreover, their both volume and surface properties are mutually different; their grain is from very-fine to medium coarse and their surface is from sintered to porous. These differences are suitable for adhesion tests because they cover wide spectrum of all possible aggregate properties. Their basic characteristics are summarized in Table 1

\subsection{Bitumen}

Paving grade bitumen 50/70 was used, standardized by [16. Two alternatives of this bitumen were made reference with no admixtures and modified containing 0.3 wt. $\%$ adhesion promoters based on chemical surfactants comprising amines.

\subsection{Mixture PREPARATION AND IMAGing}

Following technical standard 13, 12.0 $\pm 0.3 \mathrm{~g}$ of binder was heated to $170 \pm 5^{\circ} \mathrm{C}$ and then mixed together with $300 \pm 3 \mathrm{~g}$ of aggregate preheated to $160 \pm 5^{\circ} \mathrm{C}$. After prescribed 24 hours lasting technological pause, such prepared asphalt mixtures were poured with $60 \pm 3{ }^{\circ} \mathrm{C}$ stripping water for 60 minutes. Subsequently, these mixtures were subjected to visual assessment according to above cited standard. Then, they were photographed using DSLR camera Canon EOS 70D equipped with large-area sensor (APS-C $22.2 \times 14.8 \mathrm{~mm}$ ), Canon zoom lens EF-S 17-85 IS USM and polarizing circular filter Hoya HD. These pictures were used for semi-automatic adhesion assessment. Summarization of all mixtures is for clarity mentioned in Table 2

\section{AdHesion ASSESSMENT}

\subsection{VISUAL ANALYSIS}

The visual analysis, executed according to [13], is based on subjective assessment of at least two evaluators, who determine percentage of binder-coated area on aggregate within asphalt mixture (a reside is considered to be stripped areas). Their findings are compared to model cases figured in the cited standard. There are estimated 7 such cases (from A to G and from $100 \%$ to less than $20 \%$ of binder-coated areas) of stripping. It has to be stressed out that their findings can be inaccurate.

\subsection{Grey LeVel thresholding}

This assessment is based on recognition of brightness and shadows on digital image of asphalt mixtures. The areas being brighter than the dark bituminous binder are considered to be parts of stripped aggregate 


\begin{tabular}{ccccc}
\hline Quarry & Fraction & Rock & Grain & Surface \\
\hline Brant & & Granodiorite, paleo-porphyrite & Fine & Porous \\
Zbraslav & $8-16 \mathrm{~mm}$ & Proterozoic spiliness, metaphrash & Very fine & Porous \\
Skuteč & & Amphibolic-biotic granodiorite & Medium-coarse & Sintered \\
\hline
\end{tabular}

TABLE 1. Basic properties of aggregate used.

\begin{tabular}{ccc}
\hline Mixture & Aggregate & Adhesion promoters [wt. \% to binder] \\
\hline BR & \multirow{2}{*}{ Brant } & 0 \\
BM & & 0.3 \\
ZR & Zbraslav & 0 \\
ZM & & 0.3 \\
SR & Skuteč & 0 \\
SM & & 0.3 \\
\hline
\end{tabular}

TABLE 2. Asphalt mixtures summarization.

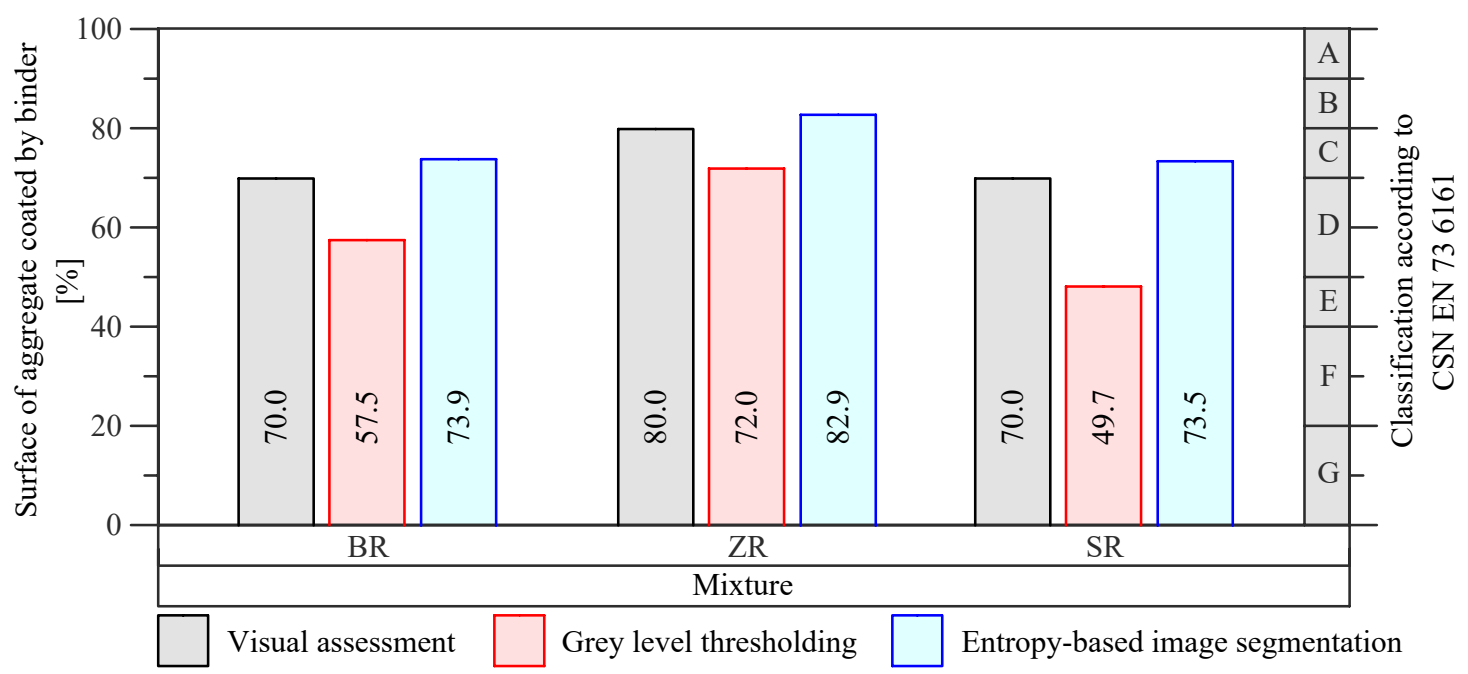

Figure 2. Assessment of adhesion between reference bituminous binder and three types of aggregates.

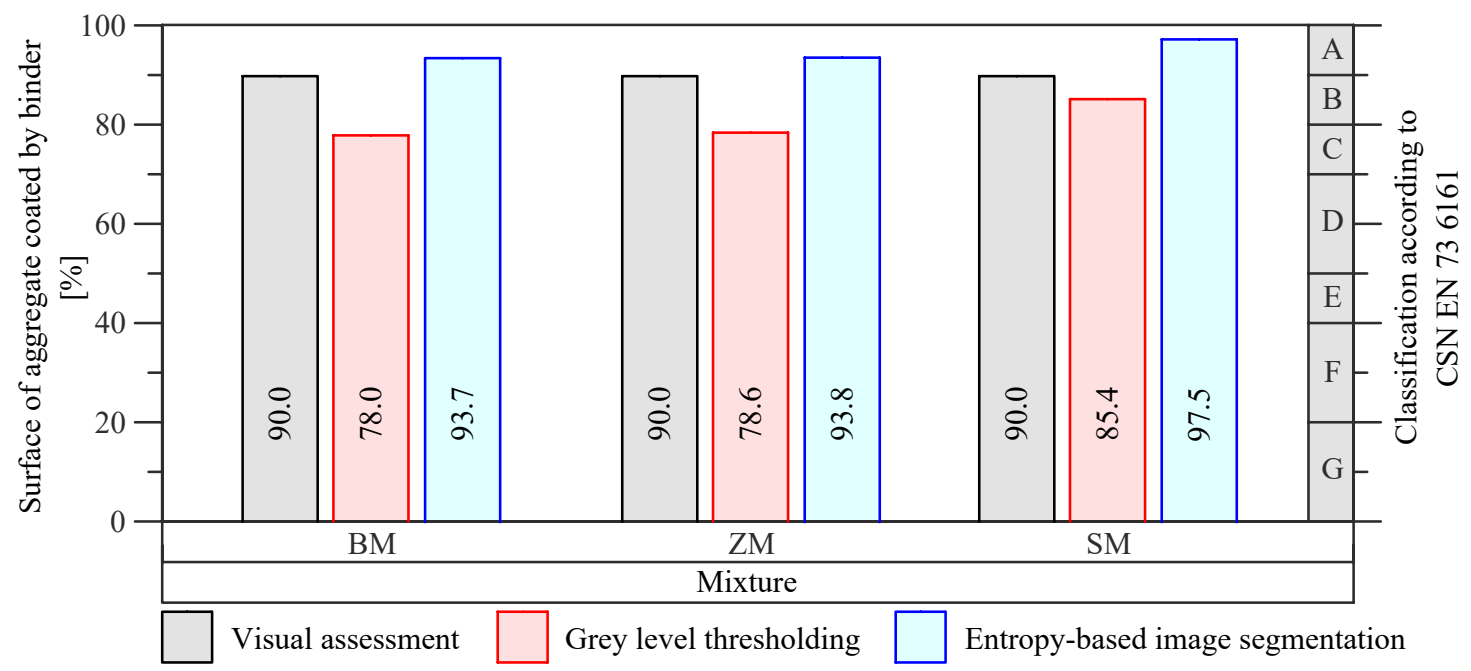

FiguRE 3. Assessment of adhesion between modified bituminous binder and three types of aggregates. 
particles. As indicated in Introduction (Chapter 1), such an approach can be misleading; if aggregate particles are rather dark, the software can define them as binder-coated. On the other side, if bitumen surfaces reflect light specularly, their captured picture is relatively bright so the areas of aggregate assessed by the software are then considered to be stripped.

\subsection{ENTROPY-BASED IMAGE SEGMENTATION}

Similarly to gray level thresholding, this method is also based on the digital image analysis. Its main principle rests on local entropy calculation in order to assess roughness of the texture. Although this method is computationally more demanding than that based on brightness/shadows recognition, it is still feasible, and primarily, it produces much more accurate outcomes independent on issues relating with light reflection from binder surfaces. Consequently, an input image can be slightly under-exposed in order to eliminate over-exposed areas but only to such an extent to dark areas to be readable for the digital camera. The software is available in [17.

\section{Results AND Discussion}

\subsection{BRANT}

It is clear from Figure 2 and Figure 3 that the adhesion between reference binder and Brant aggregate, classified according to [13], was marked as "D" - coated area up to $70 \%$ (stripped edges, stripped small spots on other areas), while that was increased up to $90 \%$, classification "B" (aggregate particles coated slightly, edges, corners, and small spots may be stripped) if adhesion promoters were used. When assessed by gray level thresholding based software, the examined coated area reached almost to $60 \%$ and $80 \%$ in the case of using reference and modified binder, respectively. While when the adhesion was assessed using entropy-based image segmentation, the area was over than $70 \%$, respectively $90 \%$.

\subsection{ZBRASLAV}

The adhesion between binder and Zbraslav aggregate was, in accordance with [13, classified as "C" (80\%stripped edges and corners, residue well coated) and "B", when reference and modified binder was used, respectively. In the case of GLT analysis, the area was between $72-79 \%$, regardless to binder type. On the other side, when it was assessed using entropybased image segmentation, the area slightly exceeded $70 \%$, resp. $80 \%$. The results are summarized in Figure 2 and Figure 3.

\subsection{SKUTEČ}

The total of binder-coated areas on Skuteč aggregate, consistent with methodology referred to in [13, was equal to "D" and "B" in the case of reference and modified binder used, respectively. When GLT analysis was employed, that was approximately $50 \%$, resp. $85 \%$, while results from entropy-based image segmentation were equal to almost $75 \%$, resp. fewer $100 \%$. These results are also summarized in Figure 2 and Figure 3 Moreover, for clarity, captured images of asphalt mixtures made from Skuteč aggregate and reference binder and their preview of consequent assessment using the both semi-automatic methods described earlier are shown in Figure 4

\subsection{SummarizATION}

Skuteč and Brant proved to be insufficient aggregate in terms of adhesion with reference binder. This was probably caused by their rock-origin; these aggregates, composed namely of acidic rocks, are typical for their fissile surface with high surface energy. On the other side, Zbraslav exhibited high affinity for bituminous binder. If adhesion promoters were used, all three aggregates were coated by binder significantly better (in some cases by more than $20 \%$ ).

After results comparison, it was shown that conventional visual analysis provided very similar results to entropy-based image segmentation; their results differed on average by $2.1 \%$ only. On the other side, grey level thresholding analysis showed to be inaccurate, if compared to other two methods. Such obtained results differed by up to $15 \%$. This was attributed to issues connected with difficulty during asphalt mixture imaging. When the light turned out on the shiny surface of binder, it is then reflected back and causes bright areas in an image. These were next assessed as stripped areas by the software. High occurrence of such areas is captured in Figure 4

\section{Conclusions}

Three types of aggregate at the fraction of 8-16 mm - Brant, Skuteč, and Zbraslav - were covered by reference and by adhesion promoters modified paving grade bitumen 50/70 for production of asphalt mixture samples to be tested and assessed in terms of adhesion between the two materials. The rate of binder coated areas onto aggregate particles was assessed using three different approaches, concretely by: (i) conventional visual analysis executed according to standardized procedure, (ii) grey level thresholding semi-automatic analysis evaluating a ratio between shadows and brightness in digital image of the mixture, and (iii) entropy-based image segmentation evaluating roughness of image texture. Following results were found:

- Skuteč and Brant aggregate showed to be unsatisfactory in intarphase interaction with reference binder. Binder-coated area was approximately 50-70\% in both cases, depending on the method employed. If adhesion promoters were used, the adhesion increased by ca. $20 \%$.

- Zbraslav exhibited high affinity for reference binder. The coated area was equal to ca. $80 \%$ and $90 \%$ in case od reference and modified binder, respectively. 

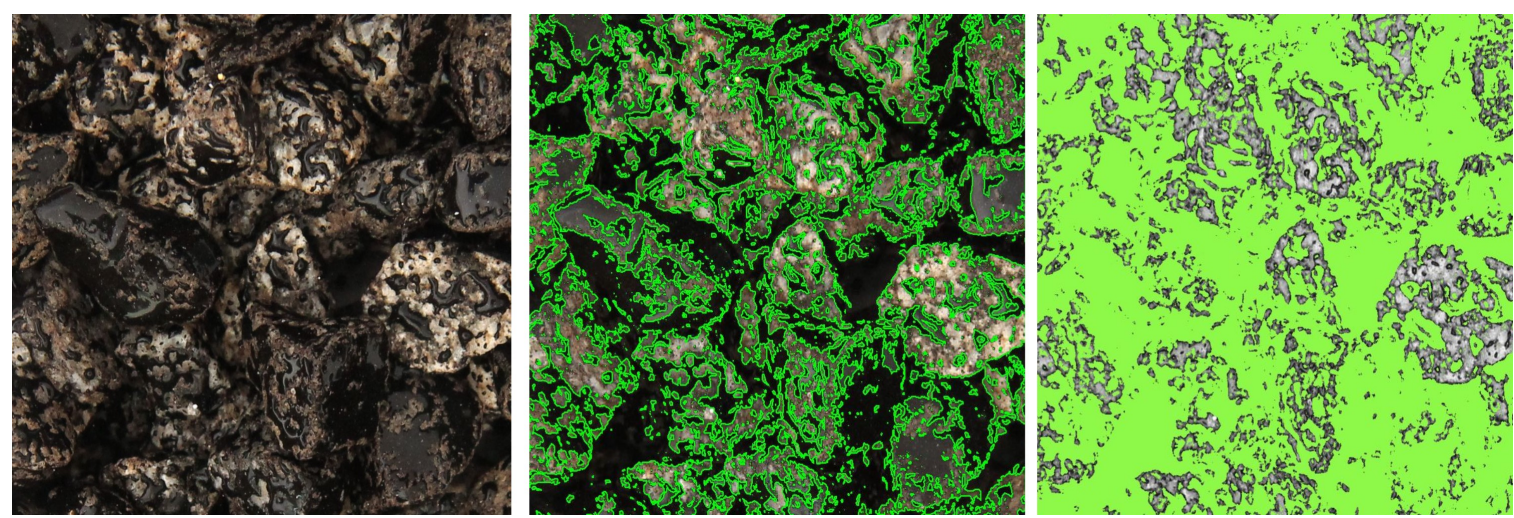

FiguRE 4. Images of aggregate Skuteč covered by reference binder, from left: original photo, gray level thresholding-, and entropy-based image segmentation.

- Grey level thresholding was intended as the least accurate, if compared to other two methods. This method was not able to recognize bright bitumen areas in captured image, caused by light reflection, as binder-coated.

\section{ACKNOWLEDGEMENTS}

This work was supported by the Czech Science Foundation (research project No. 18-13830S) and by the Czech Technical University (No. SGS16/201/OHK1/3T/11) and the support is gratefully acknowledged. Special thanks to Tereza Horová for research assistance and to Dr. Václav Nežerka for the software development.

\section{REFERENCES}

[1] S. Liu, A. Shukla, T. Nandra. Technological, environmental and economic aspects of asphalt recycling for road construction. Renewable and Sustainable Energy Reviews 75:879-893, 2017. DOI:10.1016/j.rser.2016.10.080

[2] B. Amit. Development of methods to quantify bitumen-aggregate adhesion and loss of adhesion due to water - PhD thesis. Texas A\&M University, 2006.

[3] N. Ahmad. Asphalt mixture moisture sensitivity evaluation using surface energy parameters - PhD thesis. The University of Nottingham, 2011.

[4] C. Rossi, B. Teltayev, R. Angelico. Adhesion promoters in bituminous road materials: A review. Applied science 7(524), 2017. DOI:10.3390/app7050524

[5] S. Cui, B. Blackman, A. Kinloch, A. Taylor. Durability of asphalt mixtures: Effect of aggregate type and adhesion promoters. International Journal of Adhesion and Adhesives 54:100-111, 2014. DOI:10.1016/j.ijadhadh.2014.05.009

[6] T. Valentová, J. Altman, J. Valentin. Impact of asphalt ageing on the activity of adhesion promoters and the moisture susceptibility. Transportation Research Procedia 14:768-777, 2016. DOI:10.1016/j.trpro.2016.05.066

[7] C. Rossi, P. Caputo, N. Baldino, et al. Effects of adhesion promoters on the contact angle of bitumenaggregate interface. Transportation Research Procedia 14:768-777, 2016. DOI:10.1016/j.ijadhadh.2016.07.013
[8] C. Rossi, P. Caputo, N. Baldino, et al. Quantitative evaluation of organosilane-based adhesion promoter effect on bitumen-aggregate bond by contact angle test. International Journal of Adhesion and Adhesives 72:117-122, 2017. DOI:10.1016/j.ijadhadh.2016.10.015

[9] J. Grönninger, M. Wistuba, P. Renken. Adhesion in bi tumen-aggregate-systems. Road materials and pavement design 11(4):881-898, 2010. DOI:10.1080/14680629.2010.9690311

[10] A. Khan, P. Redelius, N. Kringos. Evaluation of adhesive properties of mineral-bitumen interfaces in cold asphalt mixtures. Construction and Building Materials 125:1005-1021, 2016. DOI:10.1016/j.conbuildmat.2016.08.155.

[11] J. Yi, X. Pang, D. Feng, et al. Studies on surface energy of asphalt and aggregate at different scales and bonding property of asphalt-aggregate system. Road Materials and Pavement Design 19(5):1102-1125, 2016. DOI:10.1080/14680629.2017.1300597.

[12] ČSN EN 12697-11: Bituminous mixtures - Test methods for hot mix asphalt Part 11: Determination of the affinity between aggregate and bitumen, Praha: Czech Office for Standards, Metrology and Testing, 2006.

[13] ČSN EN 76 6161: Determination for adhesion of asphaltic binders to aggregate, Praha: Czech Office for Standards, Metrology and Testing, 2000.

[14] H. Källén, A. Heyden, K. Åström, P. Lindh. Measuring and evaluating bitumen coverage of stones using two different digital image analysis method. Measurement 84:56-67, 2016. DOI:10.1016/j.measurement.2016.02.007

[15] R. Lamperti, C. Lantieri, C. Sangiorgi, et al. Semiautomatic evaluation of the degree of bitumen coverage on bitumen-coated aggregates. In Conference Proceeding of 8th RILEM International Symposium. RILEM Bookseries, 2016. DOI:10.1007/978-94-017-7342-3_2.

[16] ČSN EN 12591: Bitumen and bituminous binders Specifications for paving grade bitumens, Praha: Czech Office for Standards, Metrology and Testing, 2009.

[17] V. Nežerka. Software Python Phase Analyzer based on Image Segmentation [online], available online: http://mech.fsv.cvut.cz/nezerka/software.html. 